\title{
Sobreposições cefalométricas de Ricketts
}

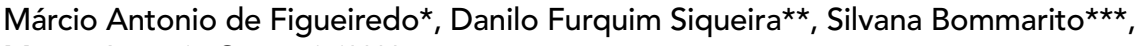 \\ Marco Antonio Scanavini ${ }^{\star \star \star \star}$
}

\begin{abstract}
Resumo
O sucesso ou o fracasso do tratamento ortodôntico realizado em pacientes na fase de crescimento têm sido muitas vezes justificado pelo padrão e pela variabilidade que este crescimento pode apresentar. Compreender estas mudanças decorrentes do crescimento e separá-las das mudanças impostas pelo tratamento ortodôntico-ortopédico facial é o objetivo deste trabalho. Ilustramos o método de sobreposição cefalométrica desenvolvido por Ricketts, aplicado às características de uma paciente com má oclusão de Classe II, $1^{\text {a }}$ divisão esquelética, tratada aos 9 anos e acompanhada até os 18 anos. O uso das sobreposições permite entender os efeitos da mecânica utilizada para a correção da Classe II, bem como do crescimento ocorrido.
\end{abstract}

Palavras-chave: Ortodontia. Sobreposição. Cefalometria. Crescimento facial.

\section{INTRODUÇÃO E REVISÃO DE LITERATURA}

A possibilidade de estudar as mudanças do crescimento facial e as modificações impostas pelo tratamento ortodôntico-ortopédico facial surgiu em 1931, quando Broadbent ${ }^{1}$ publicou seu primeiro trabalho sobre radiografia cefalométrica, utilizando um posicionador de cabeça denominado de cefalostato. Este aparelho mantinha o indivíduo numa posição fixa e reproduzível. Assim as radiografias passaram a ser padronizadas o que possibilitou o estudo em série e a análise das mudanças esqueléticas e dentárias dos pacientes. Duas ou mais radiografias cefalométricas poderiam ser sobrepostas em pontos de referência estáveis e as mudanças no crescimento observadas. Isto levou a inúmeros mé- todos de sobreposição utilizando diferentes pontos de referência com o intuito de melhor compreender estas mudanças.

Provavelmente, o método mais comum é sobrepor a base craniana anterior ao longo da linha S-N. Tweed $^{27}$ e Gianelly et al. ${ }^{10}$ utilizaram a linha S-N com o ponto de referência em Sela para determinar as mudanças gerais que ocorreriam no complexo craniofacial. Por outro lado, Proffit ${ }^{19}$ recomendou que quando houvesse diferença no comprimento da base craniana, o ponto de referência para sobreposição deveria ser o ponto Násio. Em contrapartida o método de De Coster $^{5}$ não utilizava a linha $\mathrm{S}-\mathrm{N}$ e sim as estruturas anatômicas presentes entre a metade anterior da sela turca e a região do fora-

\footnotetext{
Especialista em Ortodontia e Mestrando do Programa de Pós - Graduação em Odontologia - Área de Concentração em Ortodontia da Universidade Metodista de São Paulo - UMESP.

Doutor em Ortodontia pela FOB-USP e Professor do Programa de Pós-Graduação em Odontologia (Mestrado) - área

*** Doutora em Distúrbios da Comunicação Humana pela UNIFESP e Professora Titular do Programa de Pós-Graduação em Odontologia (Mestrado) - área de concentração em Ortodontia da UMESP.

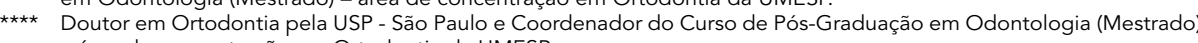
- área de concentração em Ortodontia da UMESP.
} 
mem cego. Esta região, segundo o autor, poderia ser utilizada para estudos longitudinais, por ser estável durante o crescimento craniofacial.

Bjork e Skieller ${ }^{2}$ após os seus estudos com implantes concluíram que, "as sobreposições clássicas sobre a linha S-N não deveriam ser utilizadas, porque são áreas de aposição e de reabsorção"; recomendaram as seguintes estruturas ósseas estáveis da base anterior do crânio: lâmina crivosa e estruturas trabeculares sobre e subjacentes (imagens das células das massas laterais etmoidais), tuberosidade maxilar na sua parte superior, que constitui a parede anterior da fissura pterigomaxilar, porção vertical da grande asa do esfenóide e região ântero-inferior da sela turca.

Todos estes métodos de sobreposição, citados acima, fornecem uma visão global do crescimento facial, em especial da maxila e da mandíbula.

Para a avaliação dos dentes superiores existem vários métodos descritos na literatura: Broadbent ${ }^{1}$ sugeriu a sobreposição de dois traçados ao longo do plano palatino com o centro em ENA. O método de Riede ${ }^{20}$ utilizava a sobreposição na fossa infratemporal e na parte posterior do palato. Já Mcnamara ${ }^{17}$ e Gianelly et al. ${ }^{10}$ sugeriram que, para a sobreposição, as estruturas internas da maxila deveriam ser utilizadas como referência, ajustando-se os traçados inicial e final da melhor maneira possível. O método estrutural de Björk e Skieller ${ }^{3}$ sobrepunha as cefalometrias no contorno anterior do processo zigomático da maxila, assoalho da cavidade nasal e assoalho da órbita.

Os dentes inferiores podem ser avaliados por meio da sobreposição na borda inferior da mandíbula ao longo de Go-Me sobre as estruturas da sínfise ${ }^{9}$ ou pelo método estrutural de Björk e Skieller ${ }^{3}$, que utilizavam para sobreposição a porção da cortical externa da sínfise, entre o pogônio e o ponto $B$, a cortical interna da sínfise, o canal mandibular e o germe do segundo ou do terceiro molar. Gianelly et al. ${ }^{10}$ recomendaram que a sobreposição deveria ser feita também no contorno interno da sínfise mentoniana e no canal mandibu- lar, porém se o canal não estivesse visível, a borda inferior da mandíbula deveria ser utilizada.

Apesar do grande número de métodos disponíveis na literatura, não há um consenso de qual é o mais indicado. Julgamos importante o clínico saber o que ele quer medir e qual o local mais apropriado para esta mensuração, para tanto o conhecimento a respeito de crescimento craniofacial é imprescindível. Acredita-se que, quando houver dúvidas com relação ao resultado da técnica, uma segunda sobreposição deve ser realizada com outra técnica e os resultados comparados.

Cook, Sellke e Begole ${ }^{6}$ avaliaram a confiabilidade e a validez de algumas técnicas de sobreposição da maxila e da mandíbula. Compararam duas técnicas (para a maxila): a posição 3 de Ricketts $^{21,23,24,25}$ com a técnica de sobreposição ajustada, envolvendo digitalização de dois pontos no traçado cefalométrico do pré-tratamento, a fim de simular implantes metálicos. Para a mandíbula utilizaram a posição 4 de Ricketts ${ }^{21,23,24,25}$ com o método estrutural de Björk e Skieller ${ }^{3}$. Neste estudo chegaram à conclusão de que nenhuma das técnicas de sobreposição provou ser relevante estatisticamente, mas recomendaram a posição 3 e 4 de Ricketts $^{21,23,24,25}$ devido à facilidade de utilização.

Segundo Mcnamara ${ }^{17}$, o método de sobreposição de Ricketts ${ }^{21,23,24,25}$ além de ser utilizado para avaliar mudanças de crescimento e desenvolvimento serve para identificar erros de traçado cefalométrico.

Vale ressaltar que a análise de sobreposição cefalométrica une o conhecimento teórico a respeito do crescimento e desenvolvimento craniofacial à clínica ortodôntica. Os efeitos do tratamento ortodôntico-ortopédico facial podem ser analisados e separados do crescimento normal.

O método apresentado neste trabalho foi proposto por Ricketts $21,23,24,25$ e utiliza radiografias cefalométricas seriadas de um mesmo paciente. Com este tipo de análise, tornaram-se evidentes as alterações dentoesqueléticas ocorridas durante o tratamento e no período de contenção. 


\section{MÉTODO DE RICKETTS}

O método de Ricketts ${ }^{21,23,24,25}$ foi desenvolvido com intuito de fornecer uma base simples, ordenada e confiável, para visualizar e verificar as mudanças que ocorrem durante um o tratamento ortodôntico. As áreas de observações são: o mento, a maxila, os dentes superiores, os dentes inferiores e o perfil tegumentar. Esta análise consiste em sobrepor o traçado inicial sobre o traçado final ou qualquer traçado de um mesmo paciente em cinco locais, para identificar as alterações que se espera que ocorra devido ao crescimento, ou devido à mecânica ortodôntica. Os valores utilizados para estimativa da quantidade de crescimento, determinada pela genética, são dos estudos realizados por Ricketts ${ }^{21,22,23,24,25}$ em 1969 e em 1995.

\section{Áreas de sobreposição e avaliação}

Cinco pontos cefalométricos principais são utilizados para sobrepor os traçados: o ponto $\mathrm{Cc}$ (centro do crânio), o ponto $\mathrm{Na}$ (násio), a ENA (espinha nasal anterior), o ponto $\mathrm{Pm}$ (suprapogonio) e o ponto situado na intersecção do Plano Estético de Ricketts com o Plano Oclusal Funcional.

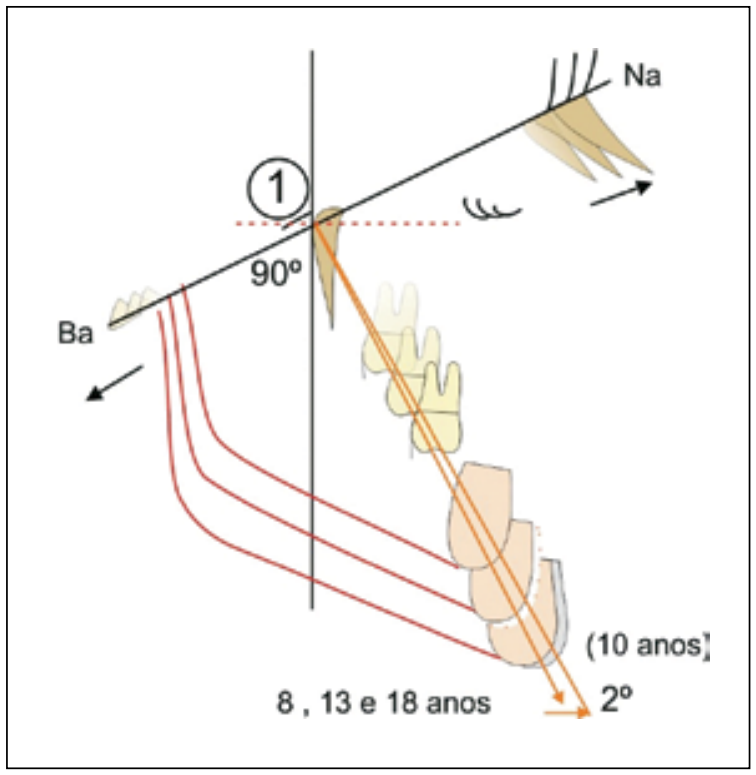

FIGURA 1 - Área de avaliação de número 1 (Básio-Násio com o centro em Cc). Observar o crescimento da mandíbula e o desenvolvimento dos primeiros molares superiores aos 8,13 e 18 anos.
Outros pontos são necessários para referência e serão descritos em detalhes posteriormente. Estes cinco pontos são utilizados para avaliar as alterações em 7 áreas. Duas avaliações do esqueleto, que correspondem à mandíbula e maxila, duas dos dentes (incisivos e primeiro molares superiores e inferiores) e uma do perfil tegumentar:

1) Mandíbula;

2) Maxila;

3) Incisivos superiores;

4) Molares superiores;

5) Incisivos inferiores;

6) Molares inferiores;

7) Perfil tegumentar.

\section{Posição 1}

A primeira avaliação é feita para identificar qualquer alteração na direção e no crescimento da mandíbula. A figura 1 ilustra o crescimento normal.

São necessários três pontos cranianos de referência para análise da alteração ortopédica da mandíbula. Estes pontos são: Básio (ponto na borda anterior do foramem magno), Násio (selecionado na sutura frontonasal) e Cc (centro do crânio). O ponto Cc (centro do crânio) é localizado prolongando uma reta que sai do ponto $\mathrm{Gn}$ (gnátio virtual) e segue até o ponto Pt (Pterigóide), localizado na entrada do foramem redondo, sendo que o local onde esta reta cruza com o plano BásioNásio é denominado Cc.

Ricketts $^{21,22,23,24,25}$, utilizando o computador, comprovou que quando as radiografias cefalométricas longitudinais de um mesmo paciente eram sobrepostas, a região da fossa esfenopalatina sofria pouca alteração, e passou a utilizar o ponto Pt como referência para estudo do crescimento facial.

A região onde se localiza o ponto Pt possui um significado biológico importante, porque coincide com o local onde ocorre a entrada do Nervo Trigêmeo ( $\mathrm{V}$ par). Este nervo distribui-se por todas as principais estruturas da face como os músculos, 
as glândulas salivares, a língua, os olhos entre outros. Estes achados levaram Ricketts ${ }^{21,22,23,24,25}$ a concluir que, o sistema nervoso central, principalmente o Nervo Trigêmio e seus ramos Oftálmico, Maxilar e Mandibular, teriam um importante papel regulador do crescimento facial, e que o crescimento da face seria guiado na direção destes nervos.

Ricketts ${ }^{21,22,23,24,25}$ utilizava a sobreposição do plano Básio-Násio do traçado inicial com o plano Básio-Násio do traçado final, coincidindo estes dois planos em Cc. Esta é a área de avaliação de número um, onde pode-se visualizar e mensurar a quantidade e a direção do crescimento da mandíbula, e o desenvolvimento dentoalveolar do primeiro molar superior.

\section{Crescimento normal da mandíbula esperado em pacientes sem tratamento}

\section{Direção do crescimento}

Segundo Langlade ${ }^{15}$ a cabeça se divide em duas partes onde o plano Básio-Násio constitui o limite do endocrânio e do exocrânio. A parte exocraniana se desenvolve segundo um cone facial, cujo eixo é, precisamente, o Eixo Facial (Cc - Gn).

Durante o crescimento facial de pacientes "normais", ou seja, aqueles que não apresentam problemas funcionais como respiração bucal, deglutição alterada, distúrbios de hábitos (postura inadequada e hábitos de sucção), entre outros, a direção de crescimento do Eixo Facial muda muito pouco, fechando $1^{\circ}$ a cada 5 anos ou na média $0,2^{\circ}$ /ano.

A alteração máxima encontrada por Ricketts $^{21,22,23,24,25}$ na direção de crescimento do Eixo Facial, foi $+2^{\circ}$ no sentido de fechamento em 10 anos.

Quantidade em milímetros do crescimento da mandíbula:

A mandíbula aumenta em média $2,5 \mathrm{~mm} / \mathrm{ano}$ dos 8 aos 18 anos ao longo do Eixo Facial como visto na figura 1 .

\section{Posição 2}

A referência para o estudo das alterações que ocorrem na Maxila é o ângulo Basio . Nasio . ponto A. Este ângulo possui em condições normais de crescimento pouca ou nenhuma alteração. $\mathrm{O}$ valor médio encontrado para este ângulo é de $63^{\circ}$. Este valor não é a informação mais relevante, pois maxilas bem posicionadas com relação ao crânio e à face podem apresentar ângulos um pouco maiores ou menores. O mais importante nesta avaliação é que independente do valor do ângulo, este permanece constante durante o crescimento normal e raramente aumenta ou diminui mais do que $1^{\circ}$ ou $2^{\circ}$.

A sobreposição é realizada coincidindo o plano Básio-Násio do primeiro traçado com o plano Básio-Násio do segundo traçado com o centro dos dois traçados no ponto Násio. Esta sobreposição indica a direção e a quantidade de crescimento da maxila e estabelece a área de avaliação de número dois (Fig. 2).

\section{Crescimento normal da maxila em pacientes sem tratamento}

\section{Modificação horizontal}

A maxila durante o crescimento se desloca para frente e para baixo, porém quando observada pelo ângulo Básio . Násio . ponto A, o ângulo se

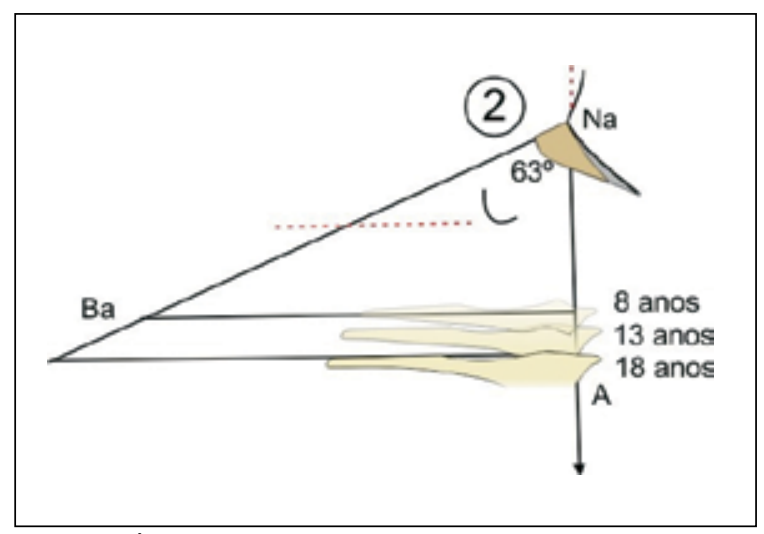

FIGURA 2 - Área de avaliação de número 2 (Básio . Násio . ponto A com 0 centro em Násio). Observar o deslocamento constante da maxila para baixo aos 8,13 e 18 anos. 
matem constante. Isto ocorre em razão da base do crânio também crescer para frente e para cima ao longo do plano Básio-Násio.

Modificação vertical da maxila

Durante o crescimento normal o plano palatino desce paralelamente a ele mesmo, devido ao crescimento nas suturas e também a remodelação que ocorre no assoalho nasal, em média $1,15 \mathrm{~mm}$ por ano.

\section{Posição 3}

A terceira avaliação é utilizada para identificar as mudanças nos incisivos e nos molares superiores, respectivamente, área de avaliação de número três e área de avaliação de número quatro (Fig. 3). Os pontos de referência utilizados são a ENA (espinha nasal anterior: ponto mais anterior do palato duro; intersecção da parte ântero-superior da maxila com o assoalho da fossa nasal) e a ENP (espinha nasal posterior: ponto mais posterior do palato duro). A técnica consiste em sobrepor o plano palatino inicial (ENA-ENP) e o plano palatino final (ENA-ENP) com o centro dos dois planos coincidindo em ENA.

\section{Desenvolvimento normal dos incisivos e primeiros molares superiores em pacientes sem tratamento \\ Quando o plano palatino é sobreposto, torna-} se possível observar o desenvolvimento vertical dos dentes superiores para baixo e para frente. Os incisivos superiores irrompem seguindo o pró-

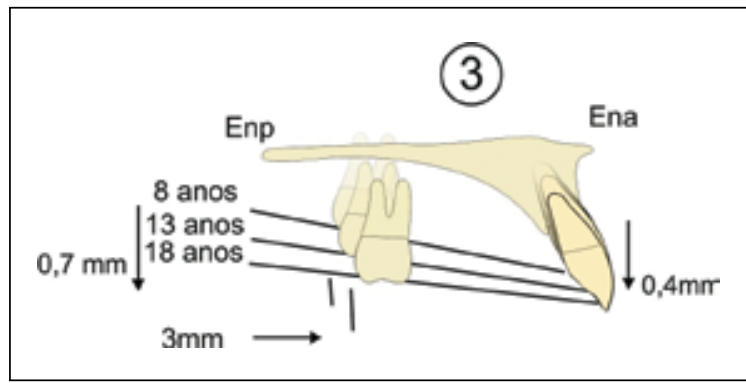

FIGURA 3 - Área de avaliação de número 3 (Plano palatino com o centro em ENA). Observar o desenvolvimento dos incisivos e dos primeiros molares superiores para frente e para baixo aos 8,13 e 18 anos. prio longo eixo $0,4 \mathrm{~mm} /$ ano e os primeiros molares superiores irrompem $0,7 \mathrm{~mm} /$ ano para baixo e $0,3 \mathrm{~mm} /$ ano para frente, seguindo o trajeto do Eixo Facial (Fig. 3).

\section{Posição 4}

A quarta avaliação é utilizada para identificar mudanças nos incisivos e nos primeiros molares inferiores. Os pontos utilizados para esta avaliação são: o ponto $\mathrm{Pm}$ (suprapogônio) e o ponto Xi. O ponto Pm é selecionado no local onde a curvatura do mento deixa de ser convexa e passa a ser côncava, sendo uma área de pouca alteração durante o crescimento. Segundo Ricketts $21,22,23,24,25$, nenhuma aposição ou remodelação parece acontecer neste local, sendo este o ponto mais estável para comparação longitudinal existente no mento. $\mathrm{O}$ ponto Xi é localizado no centro geométrico do ramo mandibular, demonstrando ser um ponto "biológico estável", pois está localizado próximo ao foramem mandibular (entrada do nervo alveolar inferior) ${ }^{22,24,25}$.

A técnica consiste em sobrepor os traçados iniciais e finais no plano $\mathrm{Xi}-\mathrm{Pm}$ com o centro dos dois traçados em Pm. Desta maneira observa-se as alterações nos incisivos inferiores e primeiros molares inferiores, respectivamente, áreas de avaliação cinco e seis (Fig. 4).

\section{Desenvolvimento normal dos incisivos e primeiros} molares inferiores em pacientes sem tratamento

Durante o crescimento normal os primeiros molares inferiores deslocam-se para cima $(0,5 \mathrm{~mm} /$ ano) e para frente $(0,3 \mathrm{~mm} / \mathrm{ano})$ e os incisivos para cima $(0,5 \mathrm{~mm} / \mathrm{ano})$ e ligeiramente para trás $(0,2 \mathrm{~mm} / \mathrm{ano})$.

\section{Posição 5}

A sobreposição cinco utiliza o plano estético formado pela união do ponto mais anterior do nariz até o ponto mais anterior do mento e o plano oclusal funcional, que passa entre as cúspides dos molares e pré-molares. Esta técnica consiste 


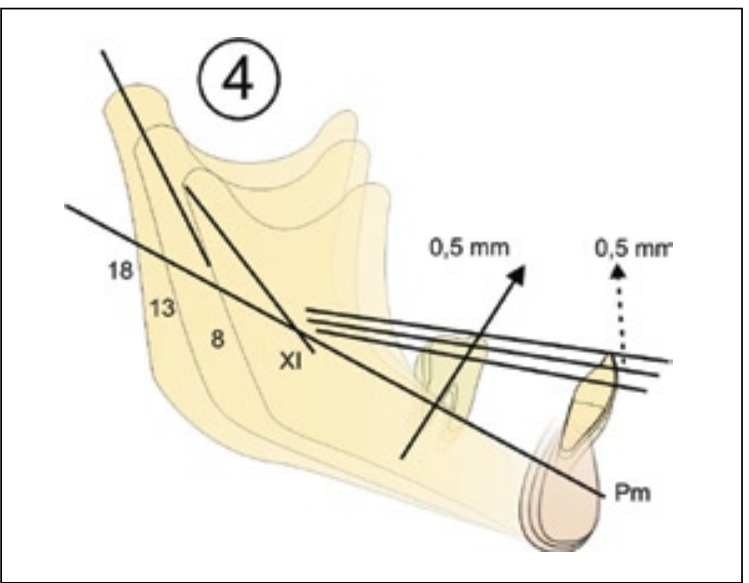

FIGURA 4 - Área de avaliação de número 4 (Xi-Pm com o centro em Pm). Observar o desenvolvimento dos incisivos inferiores para cima e ligeiramente para trás e dos primeiros molares inferiores para cima e para frente aos 8,13 e 18 anos.

em sobrepor o plano estético inicial e final com o centro na intersecção destes com o plano oclusal funcional, sendo que esta sobreposição estabelece a área de avaliação sete.

Durante o crescimento normal, a face analisada pelo Plano Estético torna-se menos proeminente, em razão do crescimento do nariz e do mento (Fig. 5, 6, 7, 8, 9).

\section{EXEMPLO CLÍNICO DA ANÁLISE DE SOBRE- POSIÇÕES}

Constatou-se durante a anamnese que a paciente R.F.C. do gênero feminino, com 9 anos e 6 meses de idade ao início do tratamento, teve amamentação materna até os 7 meses e chupou chupeta até os 6 anos de idade. No exame clínico extrabucal, observou-se falta de selamento e interposição labial, perfil convexo e corredor bucal evidente (Fig.10, 11, 12). No exame intrabucal verificou-se uma má oclusão de Classe II, $1^{\text {a }}$ divisão, com diminuição do perímetro transversal da maxila, trespasse horizontal aumentado, primeiros molares superiores com giro mesial, desvio das linhas médias e um fato muito importante, a presença de um incisivo inferior extranumerário (Fig. $13,14,15,16,17,18,19,20,21)$.

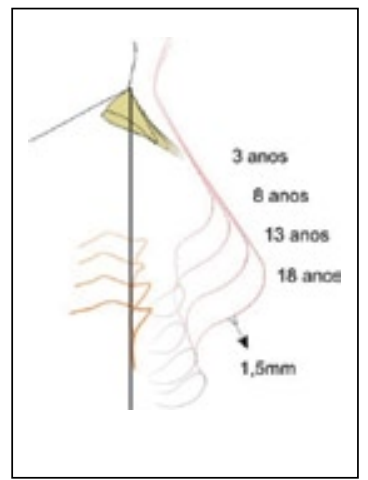

FIGURA 5 - Crescimento da base do nariz (1,5 mm/ano) dos 3 aos 18 anos.

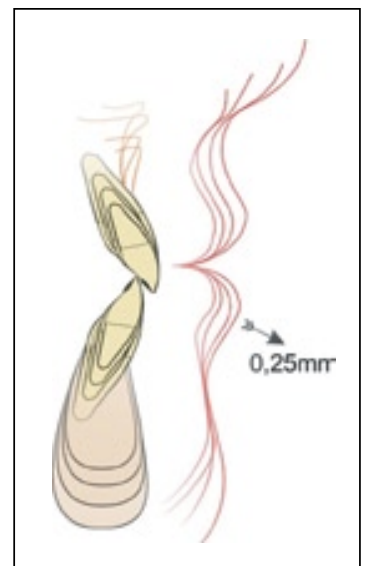

FIGURA 7 - Aumento do lábio inferior $(0,25 \mathrm{~mm} / \mathrm{ano})$ dos 3 aos 18 anos.

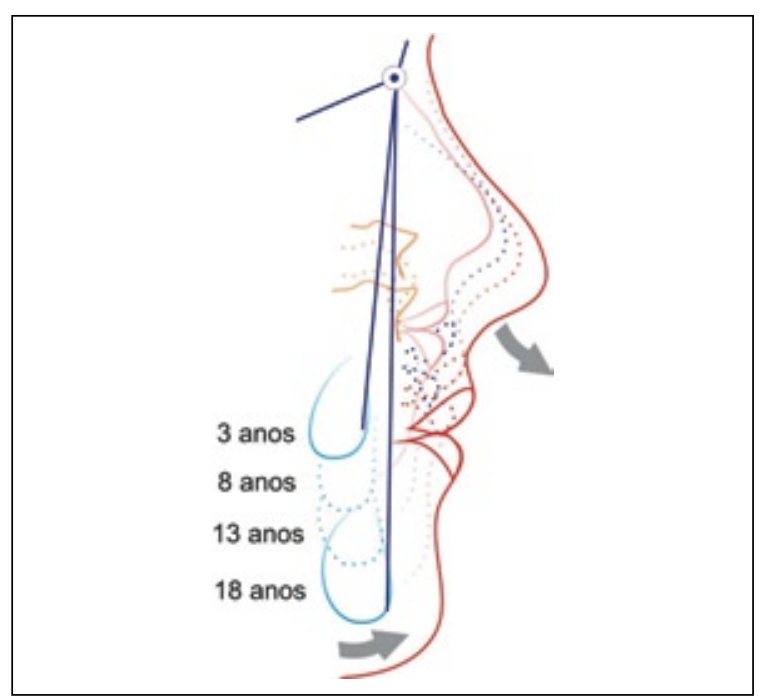

FIGURA 9 - Mudanças normais no perfil tegumentar aos 3, 8, 13 e 18 anos. 
$\mathrm{Na}$ análise cefalométrica inicial (Fig. 22) observou-se uma Classe II, $1^{\text {a }}$ divisão esquelética, com $\mathrm{ANB}=6,5^{\circ}$, profundidade maxilar $=92^{\circ}$, eixo facial $=86^{\circ}$, convexidade $=5 \mathrm{~mm}, 1-$ Apo $=3 \mathrm{~mm}$, 1.Apo $=33^{\circ}$, trespasse horizontal $=10 \mathrm{~mm}$, trespasse vertical $=1 \mathrm{~mm}$, plano palatino inclinado $=$ $5^{\circ}$, ângulo interincisivo $=108^{\circ}$, plano oclusal de Classe II (acima do ponto Xi).

Pelos modelos de estudo iniciais (Fig. 23), verificaram-se algumas distâncias inferiores segundo Ricketts ${ }^{22,24,25}$ : profundidade da arcada $=27 \mathrm{~mm}$ (norma $=24 \mathrm{~mm}$ ), distância entre os primeiros molares inferiores $=52 \mathrm{~mm}$ (norma $=55 \mathrm{~mm}$ ), distância entre os primeiros pré-molares inferiores $=38 \mathrm{~mm}$ (norma $=40 \mathrm{~mm}$ ) e distância entre os caninos inferiores $=30 \mathrm{~mm}$ (norma $=26 \mathrm{~mm}$ ).

Realizou-se o tratamento dentro dos princípios da terapia Bioprogressiva de Ricketts ${ }^{23}$, com a

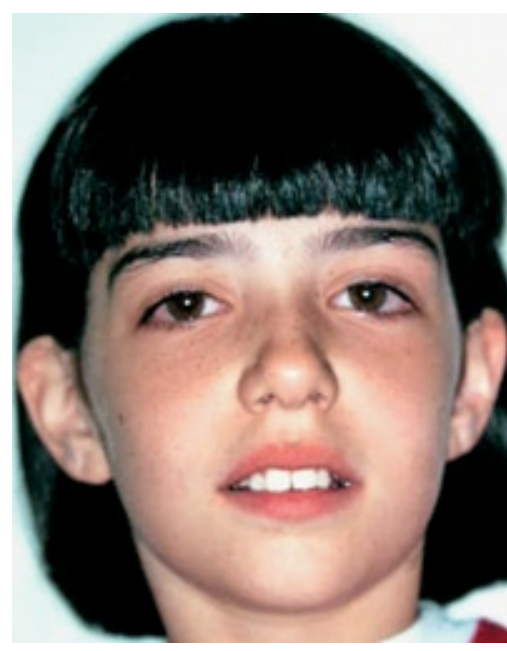

FIGURA 10 - Vista frontal da paciente ao início do tratamento, com o lábio inferior entre os incisivos.

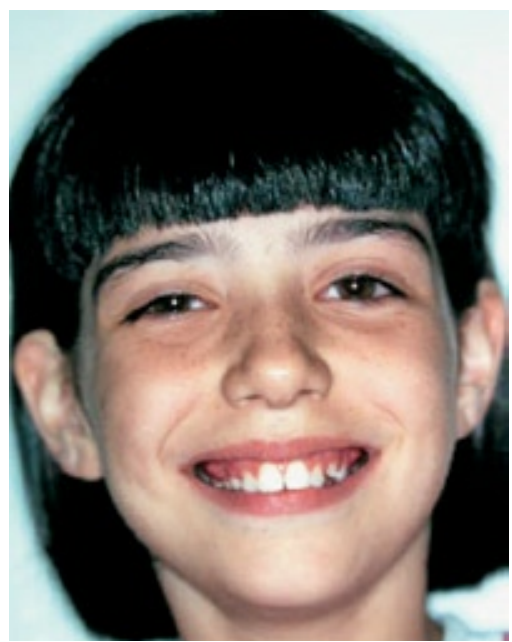

FIGURA 11 - Vista frontal da paciente sorrindo ao início do tratamento, com presença de corredor bucal escuro.

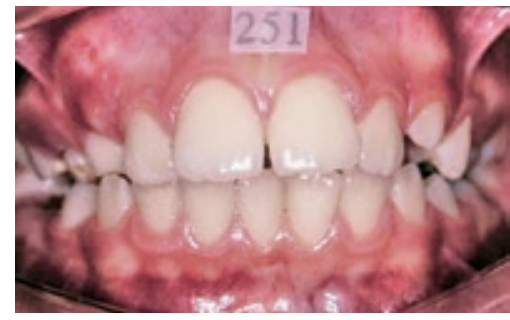

FIGURA $13,14,15$ - Vista intrabucal do início do tratamento (frente, lado direito e lado esquerdo).

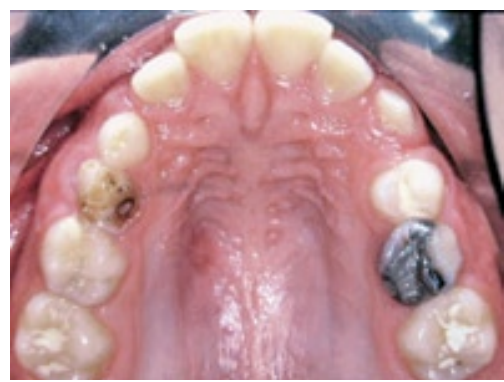

FIGURA 16 - Vista oclusal da maxila (diminuição do perímetro transversal e giro mesial dos dentes 16 e 26 ).

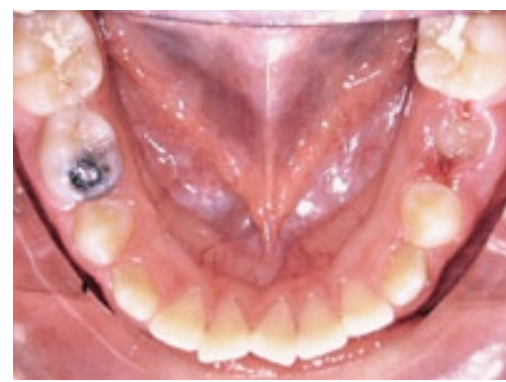

FIGURA 17 - Vista oclusal da mandíbula evidenciando a presença de 5 incisivos.

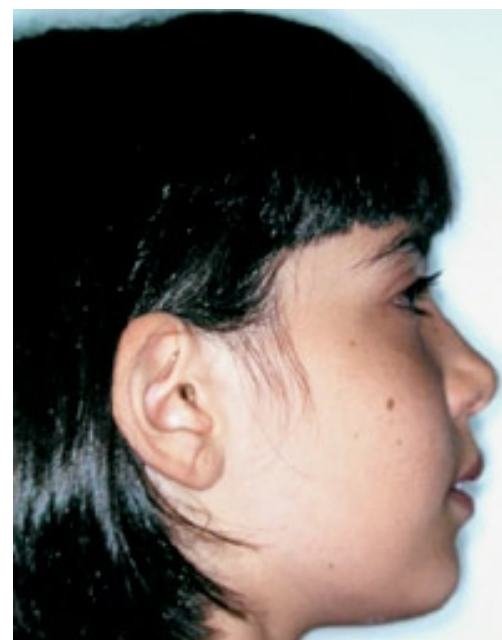

FIGURA 12 - Vista lateral da paciente ao início do tratamento, com perfil ligeiramente convexo e protrusão do lábio superior.
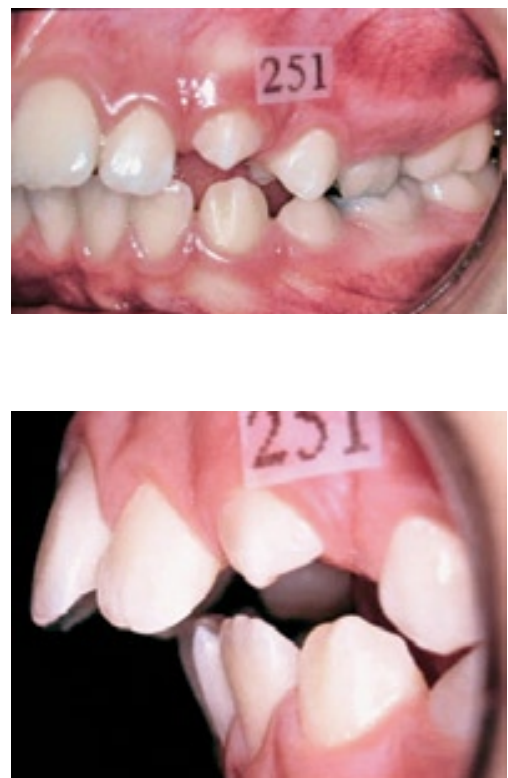

FIGURA 18 - Vista aproximada do trespasse horizontal. 

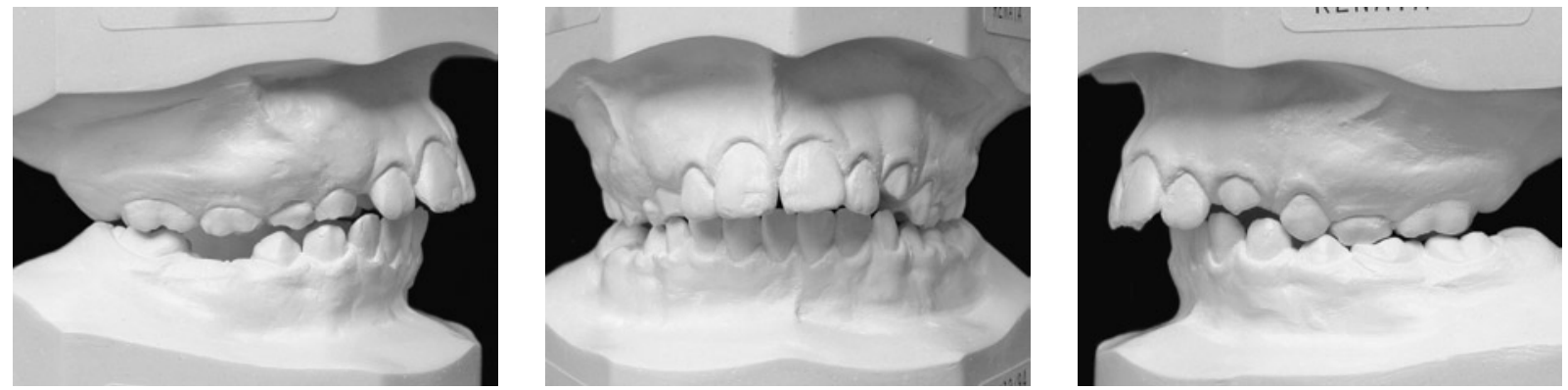

FIGURA 19,20,21 - Modelos de estudo do início do tratamento.

utilização dos seguintes aparelhos: quadrihélice, arco extrabucal de Klöen, arcos seccionais, arcos de utilidade e arcos ideais.

Os braquetes nos dentes superiores não foram colados até que a correção ortopédica com a utilização do arco extrabucal tivesse sido realizada. A paciente foi orientada a utilizar o KHG durante o período noturno (média de 8 horas), com as seguintes características: 500 gramas de força, braços externos longos (próximo ao tragus), e com inclinação de $15^{\circ}$ a $20^{\circ}$ para cima em relação ao arco interno, com o objetivo de ter a resultante de força acima do centro de resistência do molar superior evitando excessiva inclinação distal ${ }^{7,15,23}$, e arco interno expandido $1 \mathrm{~cm}$ de cada lado, como preconizado por Ricketts ${ }^{23}$, para corrigir a tendência à mordida cruzada, e também para permitir

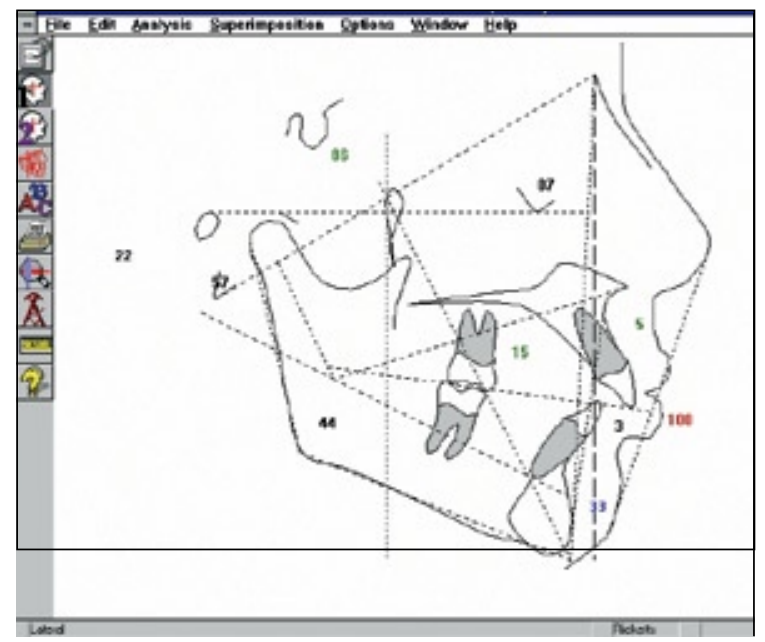

FIGURA 22 - Análise cefalométrica de Ricketts inicial. um desenvolvimento funcional do arco inferior.

Analisando os resultados obtidos (Fig. 24-36), pode-se verificar que ocorreram alterações esqueléticas e dentoalveolares, que serão descritas a seguir.

Avaliação das modificações esqueléticas e dentoalveolares entre o início do tratamento $(\mathrm{T} 1=16 / 12 / 94)$, e o final do tratamento $(\mathrm{T} 2=$ 22/04/98). Tempo decorrido entre T1 e T2: três anos e quatro meses

1) Primeira área de sobreposição: $\mathrm{Ba}-\mathrm{Na}$ com centro em CC (Fig. 37)

Nesta primeira área pode-se observar um aumento no crescimento da mandíbula de $12 \mathrm{~mm}$ ou $3,5 \mathrm{~mm} /$ ano. O valor esperado seria de $9,3 \mathrm{~mm}$ ou $2,5 \mathrm{~mm} / \mathrm{ano}$. Portanto, esta quantidade de crescimento é $2,7 \mathrm{~mm}$ maior do que a quantidade de

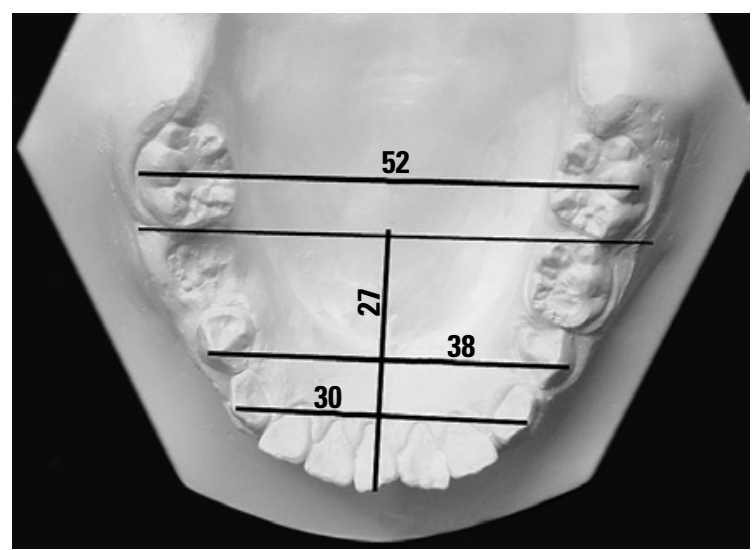

FIGURA 23 - Mensurações no modelo de estudo inicial: profundidade da arcada (distância medida de uma linha que passa pela mesial dos primeiros molares até o incisivo inferior mais anteriormente posicionado), distância intercaninos, interprimeiros pré-molares e interprimeiros molares. 

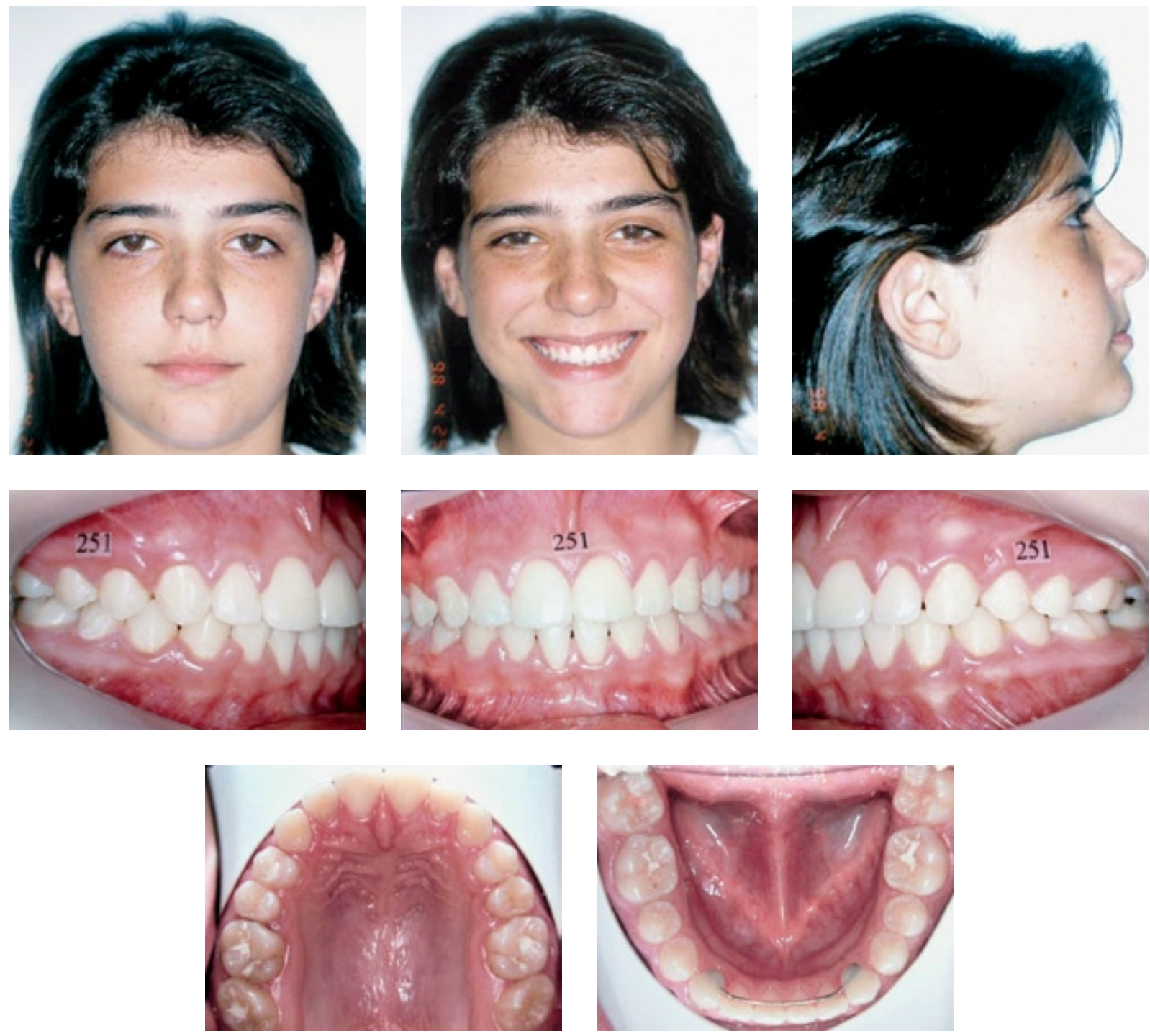

FIGURA $24,25,26,27,28,29,30,31$ - Fotos finais intra e extrabucais.

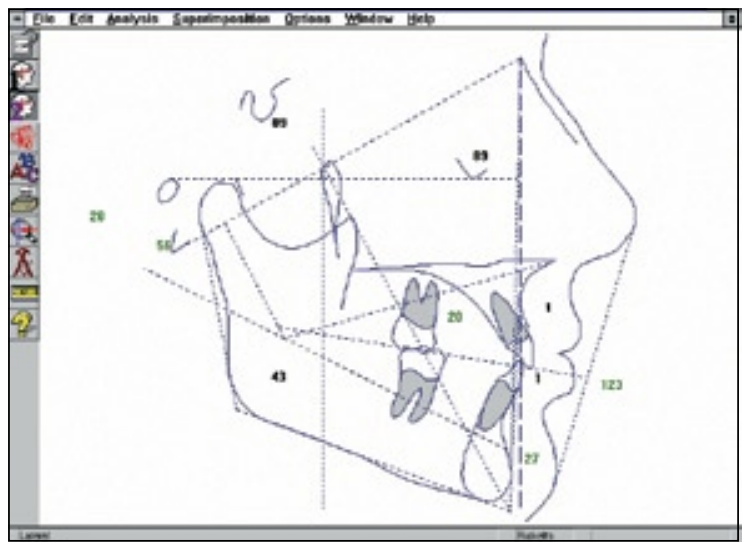

FIGURA 32 - Análise cefalométrica de Ricketts final onde se pode observar a correção da Classe II, $1^{\text {a }}$ divisão, esquelética 

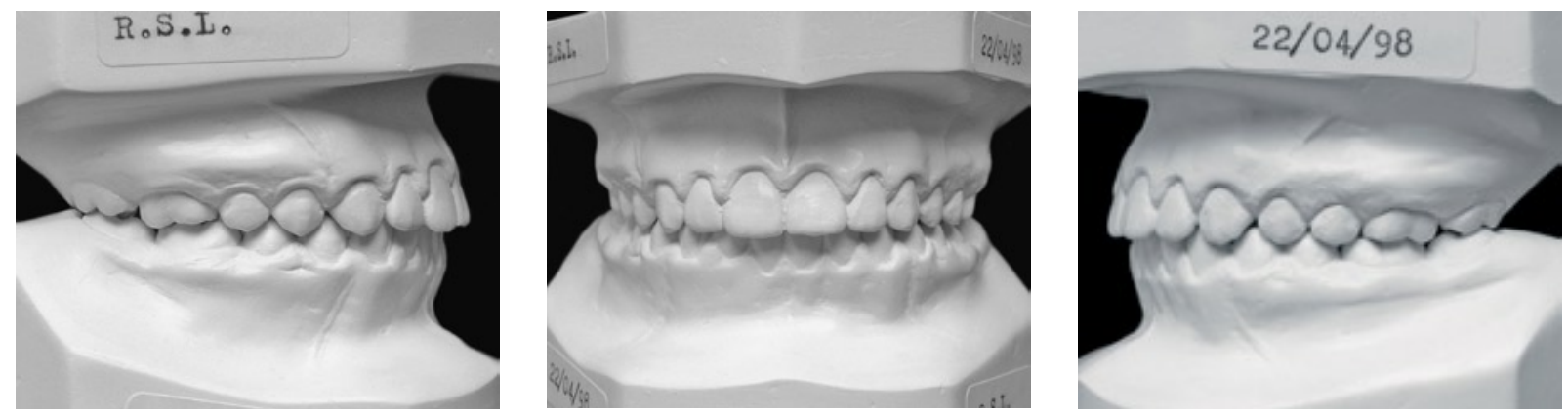

FIGURA 33, 34, 35 - Modelos de estudo do final do tratamento.

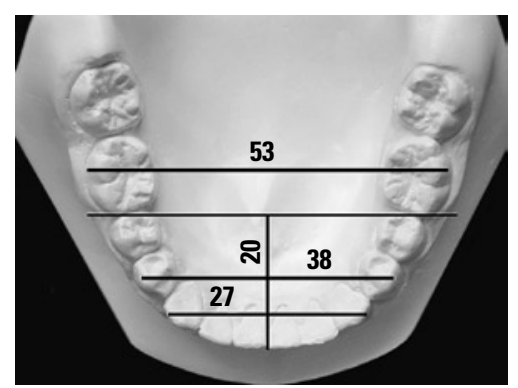

FIGURA 36 - Mensurações no modelo de estudo final: a profundidade da arcada diminuiu de $27 \mathrm{~mm}$ no início do tratamento para $20 \mathrm{~mm}$ ao final, a distância intercaninos diminuiu de $30 \mathrm{~mm}$ para $27 \mathrm{~mm}$, a distância interprimeiros pré-molares se manteve em $38 \mathrm{~mm}$ e a distância interprimeiros molares aumentou ligeiramente e foi de $52 \mathrm{~mm}$ para $53 \mathrm{~mm}$.

crescimento esperado para o período segundo os estudos de Ricketts ${ }^{21,22,23,24,25}$. Cremos que houve provavelmente um surto de crescimento neste período e, portanto, considerou-se a resposta como normal. A idade da paciente no início do tratamento ( 9 anos e 3 meses) favoreceu o resultado final. Nossos achados foram semelhantes aos encontrados por Lima Filho, Lima, Oliveira ${ }^{16}$ e Kloehn ${ }^{13}$ que, já em 1953, defendiam que a maioria dos casos bem sucedidos eram aqueles que tiveram bom crescimento durante o tratamento.

O Eixo Facial fechou $3^{\circ}$ (giro anti-horário da mandíbula), passando de $86^{\circ}$ para $89^{\circ}$ mesmo com toda mecânica extrusiva utilizada durante o tratamento (arco extrabucal cervical, quadrihélice e elásticos de Classe II). O valor máximo esperado seria um fechamento de $0,7^{\circ}$, sendo que este resultado já foi demonstrado na literatura por Cook, Sellke e Begole ${ }^{7}$ que avaliaram o controle da dimensão vertical na correção da má oclusão de Classe II, $1^{\text {a }}$ divisão, utilizando aparelho extrabucal cervical e este mesmo aparelho em conjunto com arco utilidade no arco inferior com um terceiro grupo controle. O resultado do estudo também não demonstrou abertura do plano mandibular, mesmo nos pacientes dolicofaciais. Kim e Muhl12 também estudaram o efeito do AEB cervical em 30 pacientes comparados com um grupo controle de 26 pacientes não tratados. Os autores concluíram que este estudo não suporta o dogma de que o AEB cervical causa rotação mandibular no sentido horário em decorrência da extrusão dos

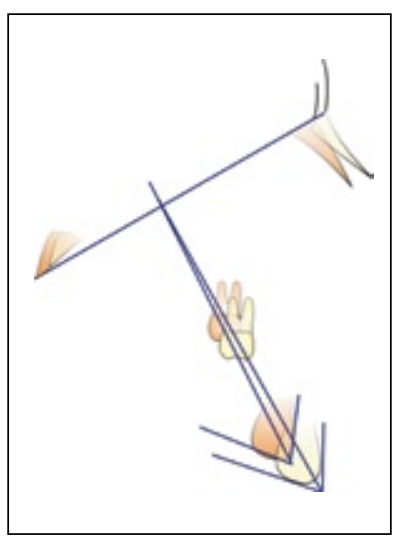

FIGURA 37 - Crescimento da mandíbula visto pelo Eixo Facial de $12 \mathrm{~mm}$ ou $3,5 \mathrm{~mm} /$ ano. Rx. inicial com cor abóbora (idade da paciente 9 anos e 3 meses) e final amarelo (idade 12 anos e 7 meses). 
molares superiores, pois as alterações verticais destes dentes foram muito semelhantes ao do grupo controle.

Os primeiros molares superiores acompanharam o deslocamento do Eixo Facial e se desenvolveram para frente e para baixo, o que normalmente ocorre durante o desenvolvimento da dentição.

2) Segunda área de sobreposição: Basio-Násio . ponto A com o centro em Násio (Fig. 38)

Nesta segunda área pode-se observar uma restrição no deslocamento anterior da maxila e o ângulo Básio-Násio com o centro em Násio diminuiu de $63^{\circ}$ para $60^{\circ}$. Diferentes pesquisadores já comprovaram este efeito com o uso do extrabucal cervical com força ortopédica ${ }^{7,8,16,23,24,26}$.

A maxila se desenvolveu no sentido vertical $8 \mathrm{~mm}$, sendo esta quantidade $4 \mathrm{~mm}$ a mais do que seria esperado para o período segundo os estudos de Ricketts ${ }^{21,22,23,24,25}$. Este aumento foi favorável para o tratamento, pois girou o plano palatino no sentido horário, aumentando a cavidade nasal. Isto ocorreu provavelmente em razão do vetor de força do AEB ser aplicado abaixo do centro de resistência da maxila (localizado perto do ápice da fissura ptérigo-maxilar ${ }^{13}$. A rotação do plano palatino no sentido horário com o uso do AEB cervical já foi descrita por Klein ${ }^{14}$; Henriques, Martins, Pinzan ${ }^{11}$; Papaioannou e Papaioannou ${ }^{18}$.

3) Terceira área de sobreposição: plano palatino inicial e plano palatino final com o centro dos dois planos coincidindo em ENA (Fig. 39)

Os primeiros molares superiores foram distalizados 2,5mm, como conseqüência da mecânica ortodôntica de Classe II (arco extrabucal e elásticos de Classe II). Este movimento distal dos primeiros molares superiores ocorreu em sentido contrário ao desenvolvimento normal do arco dentário e consideramos como efeito da mecânica de Classe II utilizada, principalmente a mecânica seccional associada ao uso de elásticos (Fig. 40,41,42). Esta mecânica permite um controle tridimensional dos caninos (movimento de corpo), com a utilização de forças contínuas e leves ${ }^{15,23}$.

Os primeiros molares superiores também extruíram $3 \mathrm{~mm}$, este valor é muito próximo dos 2,4mm considerados como desenvolvimento normal dos arcos dentários. Compulsando a literatura referente ao AEB, Ursi ${ }^{28}$; Cooke, Sellke e Begole também observaram que existe uma pequena extrusão dos molares superiores.

Os incisivos superiores também apresentaram uma pequena extrusão de $2 \mathrm{~mm}$, ou seja, $0,6 \mathrm{~mm}$ a mais do que o valor esperado e foram retraídos de corpo $8 \mathrm{~mm}$ (Fig. 39). Este movimento ocorreu em razão da mecânica utilizada no tratamento, pois durante o desenvolvimento normal dos incisivos teriam irrompido seguindo o seu longo eixo (para frente e para baixo).

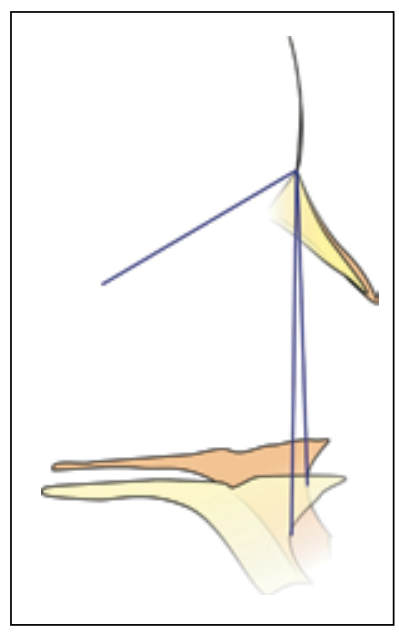

FIGURA 38 - Efeito do tratamento ortopédico na posição da maxila (restrição do deslocamento). Início com a cor abóbora e final na cor amarelo.

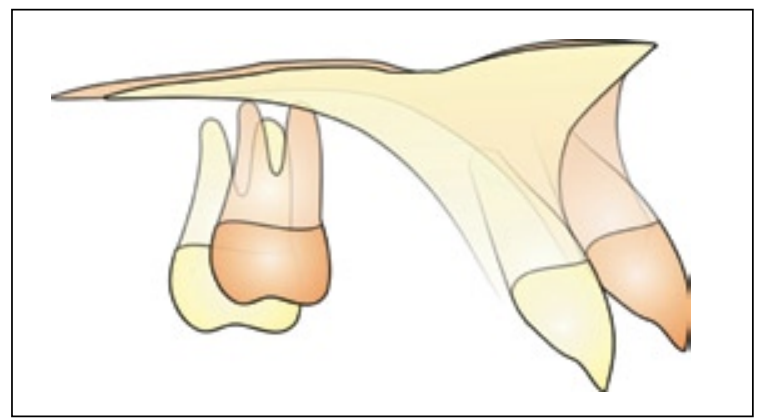

FIGURA 39 - Retração dos incisivos superiores com controle de torque (movimento de corpo) e distalização dos primeiros molares superiores. Estas mudanças se devem ao efeito do tratamento Ortodôntico-Ortopédico Facial. 

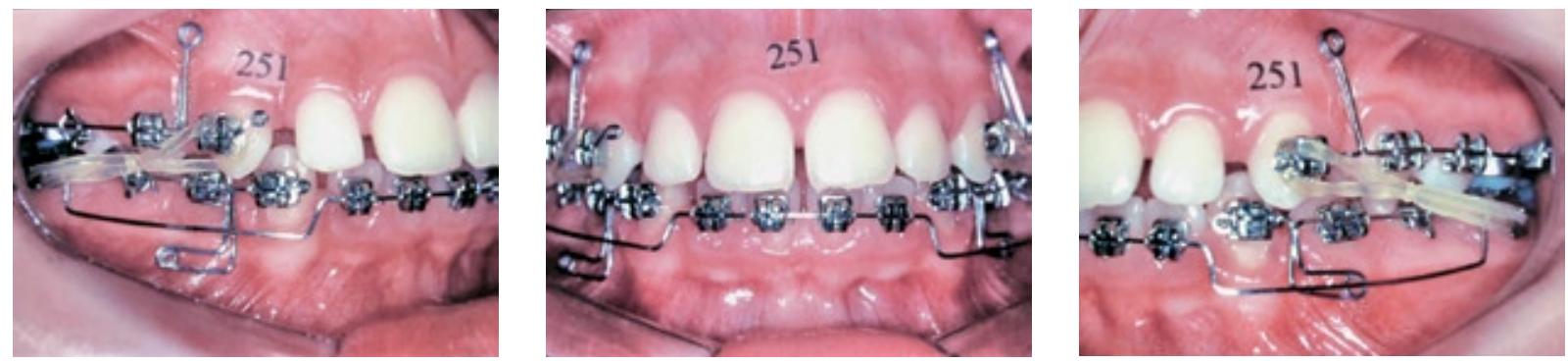

FIGURA 40, 41,42 - Mecânica de Classe II seccional, associada ao uso de elásticos. Como se pode observar a Classe II está corrigida e nenhum braquete foi colado nos incisivos superiores.

4) Quarta área de sobreposição: ao longo do Plano Xi-Pm (inicial e final) com o centro no ponto Pm (supra-pogônio) (Fig. 43)

Os primeiros molares inferiores irromperam $1,5 \mathrm{~mm}$ e mesializaram $2 \mathrm{~mm}$ durante o tratamento. Estes valores são bem próximos do esperado para o período, que seria uma irrupção dos mesmos 1,5mm, e uma mesialização de $1,1 \mathrm{~mm}$.

Este movimento mesial ocorreu em razão do tratamento ortodôntico, e colaborou para fechar o espaço da extração do incisivo inferior extranumerário e para a correção da relação molar de Classe II. Desta maneira pode-se concluir que o uso dos elásticos de Classe II não teve um efeito indesejado de extrusão dos primeiros molares inferiores durante o tratamento ortodôntico.

Os incisivos inferiores extruíram $3 \mathrm{~mm}$, ou seja, $1,1 \mathrm{~mm}$ a mais do que seria o esperado e foram retraídos $5 \mathrm{~mm}$, ou $4,25 \mathrm{~mm}$ a mais do que deveria ocorrer com o desenvolvimento normal da dentição, se nenhum tratamento tivesse sido

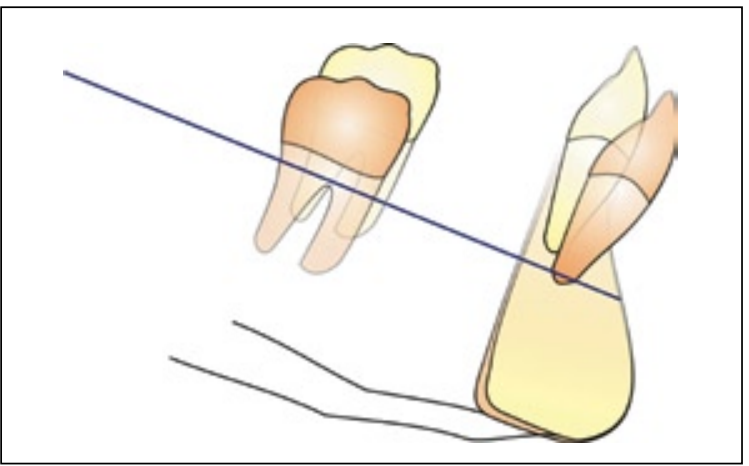

FIGURA 43 - Retração dos incisivos inferiores com controle de torque e mesialização dos primeiros molares inferiores. Início cor abóbora e final amarelo. realizado. Este movimento ocorreu como efeito do tratamento ortodôntico que fechou o espaço do incisivo inferior extranumerário.

5) Quinta área de sobreposição: intersecção do Plano Estético com o Plano Oclusal. Tl em vermelho e T2 em verde (Fig. 44)

A estética facial da paciente mudou consideravelmente após o tratamento ortodôntico-ortopédico facial como se pode verificar pela sobreposição (Fig. 44), proporcionando uma face mais harmônica, uma vez que os lábios se encontram atrás da linha estética, como preconizado por Ricketts ${ }^{22,24}$. A retração dos incisivos superiores e inferiores, observada nas figuras 39 e 43, e o crescimento do nariz e do mento implicou no posicionamento mais distal e menos proeminente dos lábios superior e inferior. Siqueira ${ }^{26}$ estudou os efeitos dentoesqueléticos e tegumentares produzidos pelo AEB cervical e encontrou uma retração do lábio superior com o uso do $\mathrm{AEB}$, porém o lábio inferior não foi influenciado por este tipo de tratamento.

Avaliação das modificações esqueléticas e dentoalveolares entre o final do tratamento (T2 $=22 / 04 / 98)$ e cinco anos e três meses após o final do tratamento $(\mathrm{T} 3=11 / 07 / 03)$. T2 em abóbora e T3 em amarelo

1) Primeira área de sobreposição: Ba-Na com centro em CC (Fig 45).

Durante este intervalo a mandíbula diminuiu o ritmo de crescimento e passou dos $3,5 \mathrm{~mm} / \mathrm{ano}$ do período de tratamento para $1,5 \mathrm{~mm} /$ ano no período 
FIGURA 44 - Mudança no perfil tegumentar da paciente em decorrência do crescimento do nariz e do mento. Inicial cor vermelha e final cor azul.

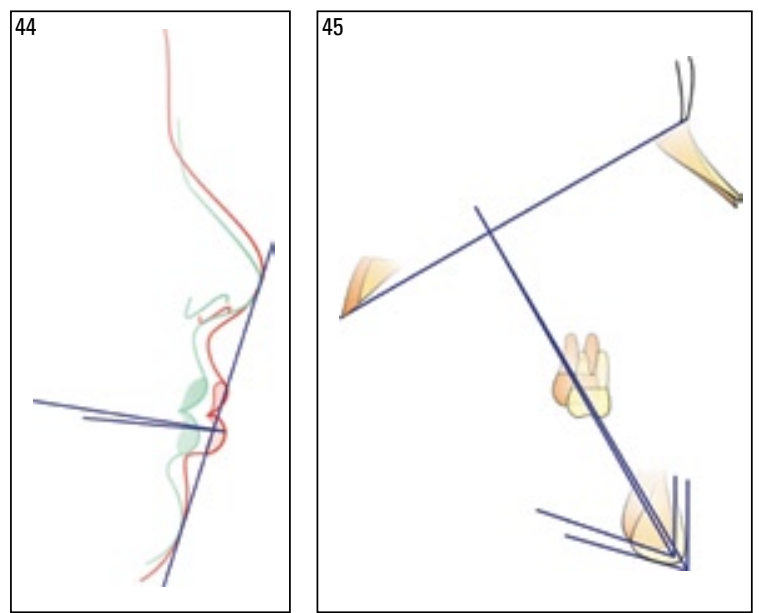

FIGURA 45 - Avaliação cefalométrica das mudanças ocorridas entre o final do tratamento e o período de acompanhamento.

de acompanhamento. Mesmo assim ainda cresceu $8 \mathrm{~mm}$, o que está em concordância com Capelozza Filho ${ }^{4}$ que descreveu que o maior crescimento obtido durante o tratamento de pacientes Classe II, é seguido por um período de menor crescimento. Isto faz com que ao final de todo crescimento, a mandíbula "tratada", apresente um tamanho similar à de indivíduos controle (não tratados).

O Eixo Facial continuou a fechar após o final do tratamento e passou de $89^{\circ}$ para $90^{\circ}$. Resposta altamente favorável, demonstrando estabilidade do resultado obtido.

Os primeiros molares superiores desenvolveram normalmente para frente e para baixo acompanhando o Eixo Facial.

2) Segunda área de sobreposição: Básio-Násio . ponto A com o centro em Násio (Fig. 46)

A maxila avançou $1,5^{\circ}$ neste período e passou $\operatorname{dos} 60^{\circ}$ do final do tratamento para $61,5^{\circ}$ no controle de 5 anos e 3 meses após o término do tratamento, esta alteração pode ser considerada normal ou como uma pequena recidiva, apesar do pequeno significado clínico.

O Ponto A permaneceu na mesma relação do final do tratamento.

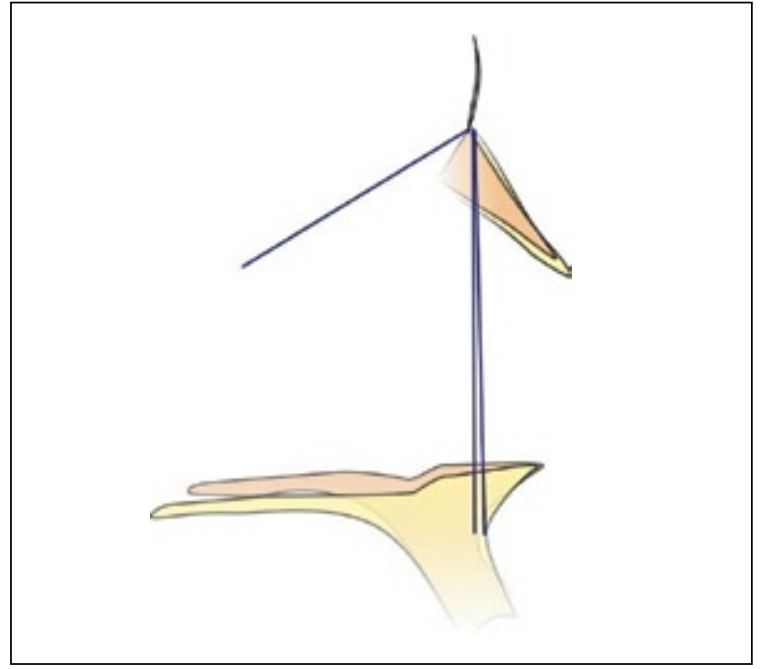

FIGURA 46 - Deslocamento anterior da maxila entre o final do tratamento (cor abóbora) e período de acompanhamento (cor amarela).

3) Terceira área de sobreposição: plano palatino final e plano palatino obtido cinco anos após o final do tratamento com o centro dos dois planos coincidindo em ENA (Fig 47)

Os primeiros molares superiores mesializaram $4,0 \mathrm{~mm}$ quando comparados com o final do tratamento, sendo que este movimento para mesial é $2,4 \mathrm{~mm}$ a mais do que seria o normal esperado para o período. Este fato pode estar relacionado com uma recidiva do movimento distal obtido durante o tratamento. Também desenvolveram no sentido vertical $3 \mathrm{~mm}$, quantidade esta ligeiramente menor do que a esperada para o período de 5 anos e 3 meses.

Os incisivos superiores se desenvolveram no sentido vertical $4 \mathrm{~mm}$ mantendo o longo eixo de irrupção, sendo este valor $2,1 \mathrm{~mm}$ maior do que o esperado.

4) Quarta área de sobreposição: ao longo do Plano Xi-Pm com o centro no ponto Pm (Fig. 48)

Os primeiros molares inferiores desenvolveram $2 \mathrm{~mm}$, valor este ligeiramente menor do que seria o esperado para o período e não houve movimento mesial após o final do tratamento.

Os incisivos inferiores desenvolveram no 


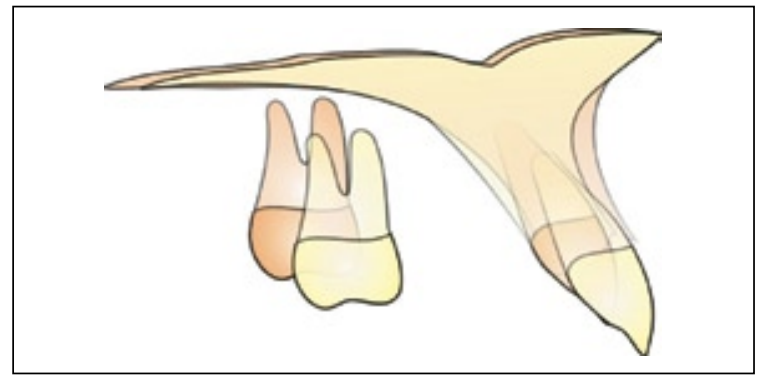

FIGURA 47 - Após o final do tratamento tanto os incisivos como os molares superiores desenvolveram mais do que o normal para o período.

sentido vertical também $2 \mathrm{~mm}$ após o final do tratamento e período de acompanhamento sem nenhum movimento vestibular ou lingual.

5) Quinta área de sobreposição: intersecção do Plano Estético com o Plano Oclusal. Tl em vermelho e T2 em verde (Fig. 49)

Durante o período de contenção as mudanças foram sutis (Fig. 49), os lábios continuam atrás da linha estética de Ricketts. Estas alterações ocorreram agora em função somente do crescimento do nariz e do mento. A face e a oclusão continuaram em harmonia como se observa nas figuras 50 até 57.

Avaliação das modificações esqueléticas e dentoalveolares entre $o$ início do tratamento ( $\mathrm{T} 1=16 / 12 / 94)$ e cinco anos após o final do tratamento $(\mathrm{T} 3=11 / 07 / 03)$. Tempo entre as radiografias oito anos e sete meses. Tl em abóbora e T3 em amarelo

1)Primeira área de sobreposição: $\mathrm{Ba}-\mathrm{Na}$ com centro em Cc (Fig. 58)

Durante T1 e T3 a mandíbula cresceu $20 \mathrm{~mm}$ ou $2,29 \mathrm{~mm} /$ ano. Esta quantidade de crescimento é considerada normal e dentro do esperado para ocorrer no período.

O Eixo Facial fechou (rotação anti-horária da mandíbula) $4^{\circ}$ e foi de $86^{\circ}$ para $90^{\circ}$, o que foi muito importante para o resultado final do tratamento ortodôntico-ortopédico facial, ajudando a correção da má oclusão de Classe II, melhorando a estética facial pela posição mais anterior

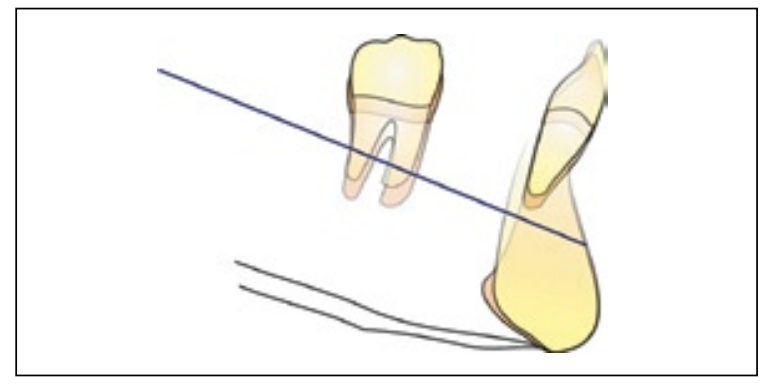

FIGURA 48 - Desenvolvimento normal dos incisivos e molares inferiores após o final do tratamento.

do mento e promovendo um trespasse vertical e horizontal adequados para a estabilidade do resultado obtido.

Os primeiros molares superiores se desenvolveram normalmente para frente e para baixo, acompanhando o Eixo Facial.

2) Segunda área de sobreposição: Básio-Násio . ponto A com o centro em Násio (Fig. 59)

Nesta segunda área pode-se observar uma restrição no deslocamento anterior da maxila. O ângulo Básio . Násio . ponto A com o centro em Násio diminuiu de $63^{\circ}$ para $61,5^{\circ}$. Apesar da pouca diferença encontrada entre T1 e T3, ela é de significado clínico importante, porque se não tivéssemos restringido o deslocamento da maxila no sentido anterior, o valor encontrado em T3

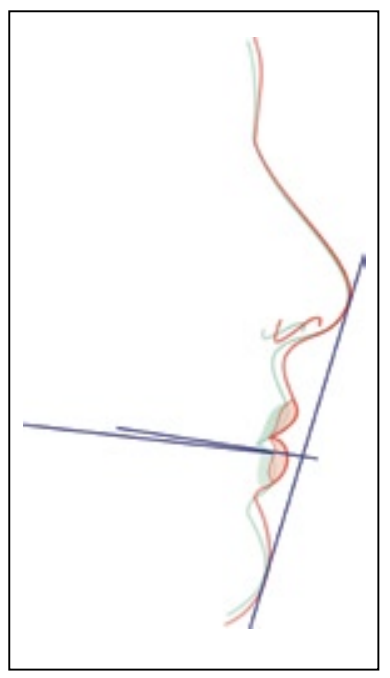

FIGURA 49 - 0 nariz e o mento continuaram a crescer após o tratamento, como era de se esperar, o que fez com que os lábios se afastassem ainda mais do plano estético. 

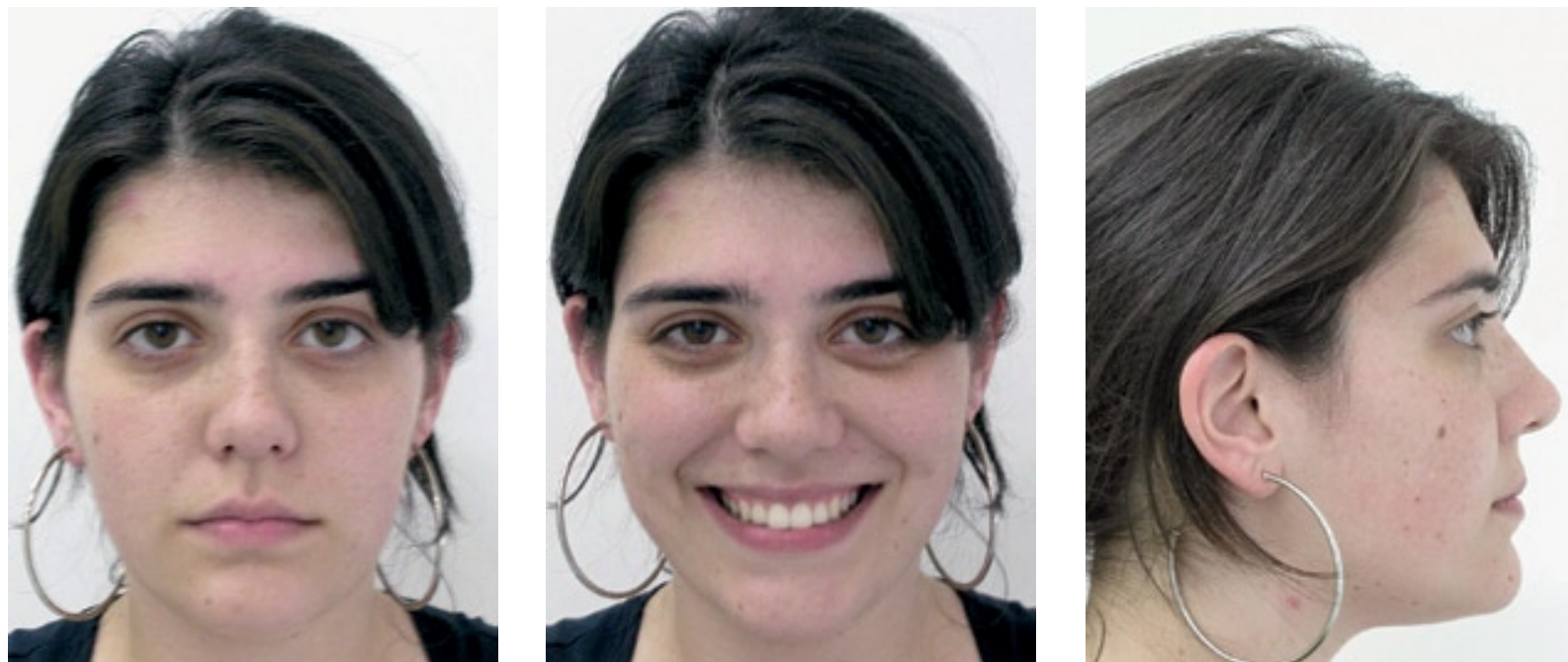

FIGURA 50,51,52 - Vista frontal, sorrindo e lateral da paciente durante o período de acompanhamento (cinco anos e três meses após o final do tratamento).
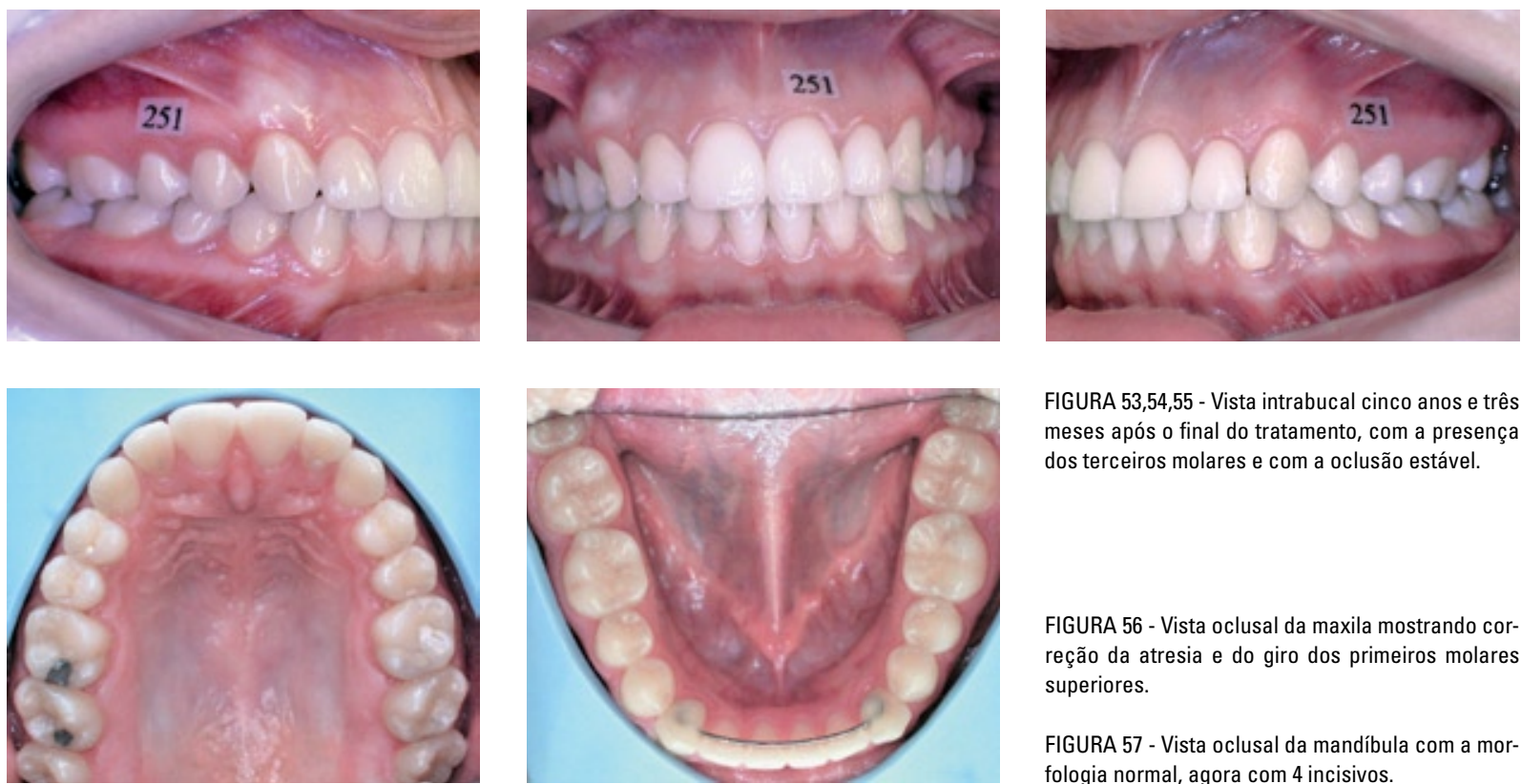

FIGURA 53,54,55 - Vista intrabucal cinco anos e três meses após o final do tratamento, com a presença dos terceiros molares e com a oclusão estável.

FIGURA 56 - Vista oclusal da maxila mostrando correção da atresia e do giro dos primeiros molares superiores.

FIGURA 57 - Vista oclusal da mandíbula com a morfologia normal, agora com 4 incisivos.

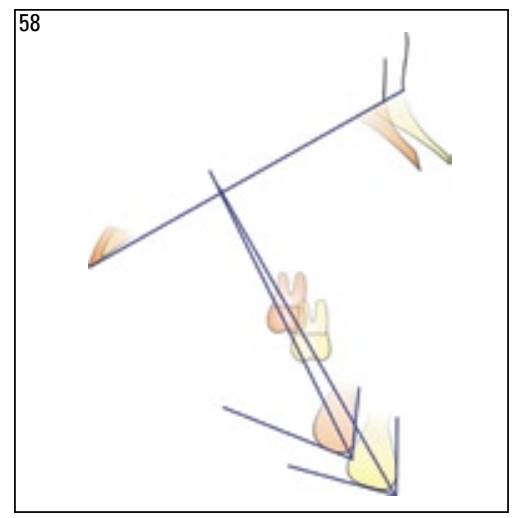

FIGURA 58 - Crescimento da mandíbula visto por meio da área de avaliação de número 1. Quantidade total de crescimento $=20 \mathrm{~mm}$, média $=2,29 \mathrm{~mm} / \mathrm{ano}$. Quantidade normal para o período e em concordância com os estudos de Ricketts que previa um crescimento de $2,5 \mathrm{~mm} / \mathrm{ano}$

FIGURA 59 - Restrição do deslocamento anterior da maxila e crescimento vertical normal para o período $(8 \mathrm{~mm})$, ou $2 \mathrm{~mm}$ a menos do que os estudos de Ricketts encontraram.

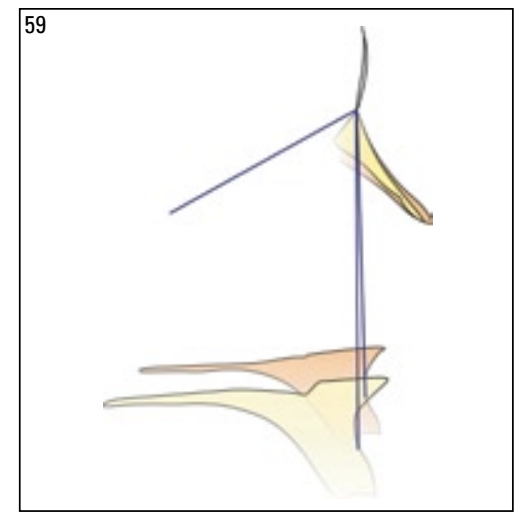




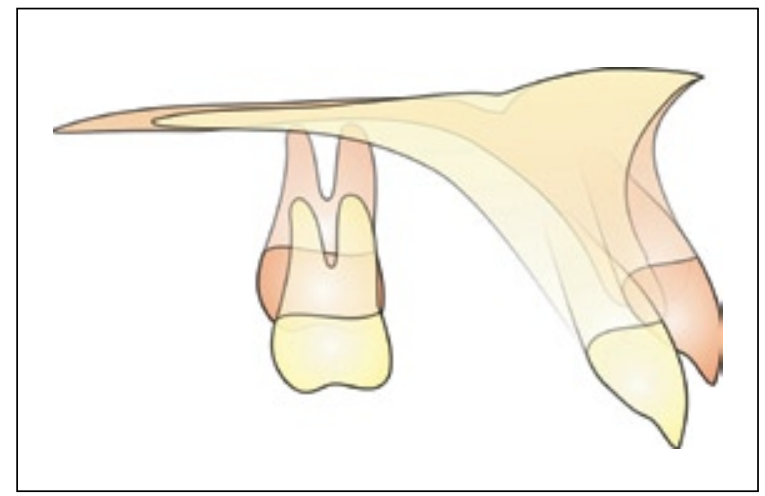

FIGURA 60 - Movimento mesial ligeiramente menor (0,22mm/ano) do que seria esperado para o período e desenvolvimento vertical também ligeiramente menor que o normal $(0,68 \mathrm{~mm} / \mathrm{ano})$.

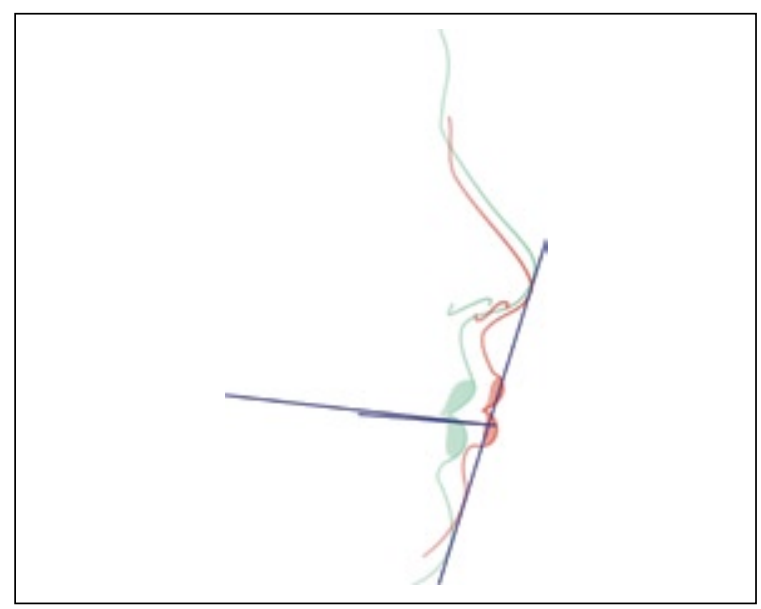

FIGURA 62 - Diminuição da protrusão dos lábios superior e inferior como conseqüência da mecânica utilizada no tratamento e pelo crescimento normal do perfil tegumentar.

seria provavelmente maior que os $63^{\circ}$ do início do tratamento. Outra observação relevante é que o ângulo Básio . Násio . ponto A diminuiu para $60^{\circ}$ durante o período ativo (T1 e T2). No sentido vertical a maxila desenvolveu $8 \mathrm{~mm}$, ou seja, $2 \mathrm{~mm}$ a menos do que seria o esperado, o que sugere que o tratamento não afetou de maneira negativa o crescimento vertical da maxila.

3) Terceira área de sobreposição: plano palatino inicial e plano palatino obtido cinco anos após o final do tratamento com o centro dos dois traçados na Espinha Nasal Anterior (Fig.60)

Os primeiros molares superiores mesializaram

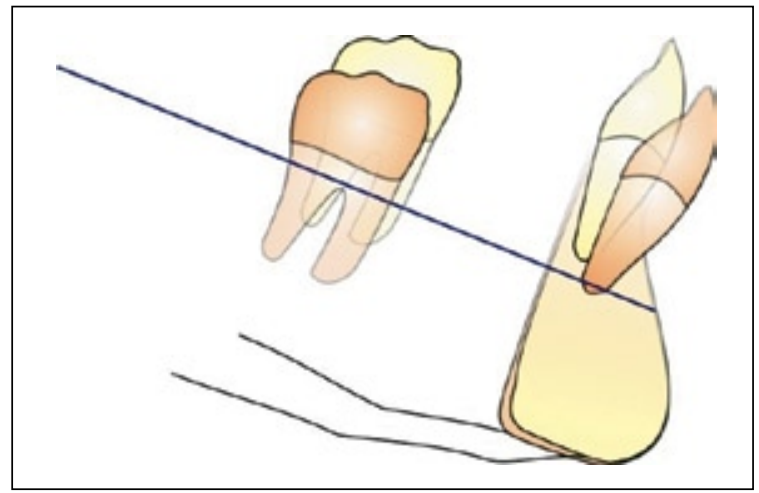

FIGURA 61 - Desenvolvimento dos dentes da mandíbula normais, com as mesmas normas encontradas nos estudos de Ricketts.

2,0mm em relação ao posicionamento do molar no início do tratamento, ou seja, este movimento para mesial é $0,6 \mathrm{~mm}$ menor do que o normal para o período e pode ser considerado como efeito da mecânica de Classe II utilizada no tratamento.

Os primeiros molares também irromperam normalmente $6 \mathrm{~mm}$ ou $0,68 \mathrm{~mm} / \mathrm{ano}$. Apesar de ter sido utilizado o extrabucal cervical durante o tratamento, não houve a longo prazo, um aumento vertical dentoalveolar (extrusão) dos primeiros molares superiores.

Os incisivos superiores foram retraídos de corpo $3,5 \mathrm{~mm}$. Este movimento ocorreu em razão da mecânica utilizada durante o tratamento, pois como visto anteriormente, os incisivos superiores se desenvolvem seguindo o seu longo eixo de irrupção.

Os mesmos incisivos superiores irromperam $6 \mathrm{~mm}$ entre T1 e T3 ou $0,68 \mathrm{~mm} /$ ano sendo que este valor é $2,8 \mathrm{~mm}$ a mais do que o esperado, porém a maior parte deste movimento ocorreu após o término do tratamento (T2 e T3) não podendo ser considerado efeito negativo da mecânica.

4) Quarta área de sobreposição: ao longo do Plano Xi-Pm (inicial e cinco anos após o final do tratamento) com o centro no ponto Pm (suprapogônio) (Fig 61)

Os primeiros molares inferiores irromperam 
$4 \mathrm{~mm}$ no sentido vertical e mesializaram $2 \mathrm{~mm}$. O desenvolvimento normal da dentição levaria o molar exatamente $4 \mathrm{~mm}$ para cima e $2,4 \mathrm{~mm}$ para frente.

Os incisivos inferiores foram retraídos $5 \mathrm{~mm}$, ou $3,4 \mathrm{~mm}$ a mais do que deveria ocorrer com o desenvolvimento normal da dentição e irromperam $4 \mathrm{~mm}$ para cima, quantidade normal para o período.

5) Quinta área de sobreposição: intersecção do Plano Estético com o Plano Oclusal (final e cinco anos após o final do tratamento). $\mathrm{Tl}$ em vermelho e T2 em verde (Fig. 62)

Pode-se observar, com esta quinta área de sobreposição, a grande mudança dos lábios em relação à linha estética de Ricketts. Este posicionamento labial cefalometricamente representa um perfil harmonioso e via de regra permite um velamento labial espontâneo. Estas mudanças ocorreram em decorrência do crescimento do nariz e do mento e da retração dos incisivos superiores e inferiores, e conseqüente acompanhamento dos lábios.

\section{CONCLUSÕES}

Pode-se verificar, com esta técnica de sobreposição, as alterações dentárias e esqueléticas decorrentes do crescimento e do tratamento ortodôntico-ortopédico facial da má oclusão de Classe II, $1^{\text {a }}$ divisão esquelética.

A mecânica utilizada não causou efeitos indesejáveis que poderiam prejudicar o resultado final, como abertura do Eixo Facial (giro horário da mandíbula), extrusão dos molares superiores e inferiores, ou inclinação do plano oclusal.

Utilizando rotineiramente este método podese compreender melhor os efeitos do tratamento e as mudanças impostas pelo crescimento e desenvolvimento facial. Conhecendo estes efeitos é possível ter uma visão clara do que se pode fazer e quais são os limites terapêuticos da mecânica ortodôntica-ortopédica facial.

Outra importante contribuição do método é compreender como o crescimento pode ajudar ou prejudicar o tratamento. $\mathrm{O}$ resultado será o aprimoramento do diagnóstico e principalmente do prognóstico ortodôntico.

No caso descrito, pode-se observar claramente as alterações dentoesqueléticas e compará-las com as normas preconizadas por Ricketts. Cabe salientar que estes valores apresentam algumas limitações, uma vez que são provenientes de medidas de outras populações. Além disto, nos padrões faciais extremos (dólico e braquifaciais severos) e nos pacientes Classe III estes dados devem ser analisados com extrema cautela, pois podem apresentar um crescimento e desenvolvimento facial acima ou abaixo da média apresentada neste estudo. Novos estudos devem ser realizados utilizando jovens brasileiros como padrão de normalidade para que se possa ter uma maior confiança nos resultados. 


\title{
Ricketts cephalometric superimposition
}

\begin{abstract}
The success or the failure of the orthodontic treatment accomplished in patients in the growth phase has been justified many times by the standard and the variability that this growth can present. Understanding these current changes of the growth and separating them from the changes imposed by the orthodontic treatment is the objective of this work. The superimposition cefalometric method developed by Ricketts will be used and applied to a patient with skeletal malocclusion Class II, first division, treated at the age of 9 years old and accompanied until the age of 18 years old. The mechanics used for the correction of the Class II was considered ideal since the obtained results were satisfactory, from the static point of view as well as the functional one. Besides, it was observed that a clockwise rotation of the jaw didn't take place in spite of the use of a Quad - helix, Elastic of Class II and Cervical headgear. Another important discovery was the great growth of the jaw that occurred between the beginning (T1) and the end of the treatment (T2) of $12 \mathrm{~mm}$ or $3,5 \mathrm{~mm} /$ year.
\end{abstract}

Key words: Orthodontics. Superimposition. Cephalometric. Facial growth.

\section{REFERÊNCIAS}

1. BROADBENT, B. H. Bolton standards and technique in Orthodontic practice. Angle Orthod, Appleton, v.7, no. 4, p. 209-233, 1937.

2. BJÖRK, A.; SKIELLER, V. Facial development and tooth eruption. An implant study at the age of puberty. Am J Orthod, St. Louis, v. 62, p. 339-383, 1972.

3. BJÖRK, A.; SKIELLER, V. Normal and abnormal growth of the mandible. A synthesis of longitudinal cefhalometric implants studies over a period of 25 years. Eur J Orthod, London, v. 5, p. 1-46, 1983.

4. CAPELOZZA FILHO, L. Diagnóstico em Ortodontia. Maringá: Dental Press Editora, 2004.

5. GHAFARI, J.; ENGEL, E. F.; LASTER, L. L. Cephalometric superimposition on the cranial base: a review and a comparison of four methods. Am J Orthod Dentofacial Orthop, St. Louis, v. 91, no. 5 p. 403-413 May 1987.

6. COOK, A. H.; SELLKE, T. A.; BEGOLE, E. A. The variability and reliability of two maxillary and mandibular superimposition techniques. Part II. Am J Orthod Dentofacial Orthop, St. Louis, v. 106, p. 463-471, 1994.

7. COOK, A. H.; SELLKE, T. A.; BEGOLE, E. A. Control of the vertical dimension in Class II correction using a cervical headgear and lower utility arch in growing patients. Part I. Am J Orthod Dentofacial Orthop, St. Louis, v. 106, no. 4, p. 376-388, Oct. 1994.

8. GANDINI JÚNIOR, L. G.; MARTINS, J. C. da R.; GANDINI, M. R. E. A. S. Avaliação cefalométrica do tratamento da Classe II, 1a divisão, com aparelho extrabucal de Kloehn, e aparelho fixo - alterações esqueléticas (Parte I). R Dental Press Ortodon Ortop Maxilar, Maringá, v. 2, n. 6, p.75-87, nov./dez. 1997.

9. GRABER, T. M.; VANARSDALL, R. L. Ortodontia princípios e técnicas atuais. Rio de Janeiro: Guanabara Koogan, 1996. p. $400-465$.

10. GIANELLY, A. A. et al. A técnica bidimensional teoria e prática. [S. I.]: GAC International, 2001.
11. HENRIQUES, J. F. C.; MARTINS, D. C.; PINZAN, A. Estudo cefalométrico da ação da ancoragem extrabucal cervical, na dentadura mista, sobre a maxila, mandíbula e dentes, em pacientes com Classe II, divisão 1. Ortodontia, São Paulo, v. 12, n. 2, p. 76-86, maio/ago. 1979.

12. KIM, K. R.; MUHL, Z. F. Changes in mandibular growth direction during and after cervical headgear treatment. Am J Orthod Dentofacial Orthop, S. Louis, v.119, no. 5, p. 522-530, May 2001.

13. KLOEHN, S. J. Orthodontics-force or persuasion. Angle Orthod, Appleton, no. 1, p. 56-65, 1953.

14. KLEIN, P. L. An evaluation of cervical traction on the maxilla and upper first permanent molar. Angle Orthod, Appleton, v. 27, no. 1, p. 61-68, Jan. 1957.

15. LANGLADE, M. Diagnóstico Ortodôntico. São Paulo: Ed Santos, 1993. p. 245-301, 1993.

16. LIMA FILHO, R. M. A.; LIMA, A. L.; OLIVEIRA, R. A. C. Mandibular changes in skeletal class II patients treated with Kloehn cervical headgear. Am J Orthod Dentofacial Orthop, St. Louis, v. 124, no. 1, July 2003

17. MCNAMARA, J. A. A method of cephalometric evaluation. Am J Orthod, St. Louis, p. 449-469, Dec. 1984.

18. PAPAIONNOU, M. O.; PAPAIONNOU, A. Comparison of treatment results with the edgewise and the Begg approach. J Clin Pediatr Dent, Birmingham, v.19, no.1, p. 27-30, 1994

19. PROFFIT, W. R. Ortodontia contemporânea. São Paulo: Pancast, 1991.

20. RIEDEL, R. A. A. Postretention evaluation. Angle Orthod, Appleton, v. 44, no. 3 p. 94-212,1974

21. RICKETTS, R. M. A four method to distinguish orthodontic changes from natural growth. J Clin Orthod, Boulder, v. 4, p. 208228, 1975.

22. RICKETTS, R. M. Provocations and perceptions in cranio-facial orthopedics. Colorado: RMO, 1989. v 1 , parte 1, 2. 
23. RICKETTS, R. M et al. Técnica bioprogressiva de Ricketts. 3. ed. Buenos Aires: Médica Panamericana, 1990.

24. RICKETTS, R. M. Cefalometria progressiva paradigma 2000. California: Instituto Americano para Educação Bioprogressiva, 1996. p. 64-120

25. RICKETTS, R. M. Consummate occlusion. California: American Institute for Bioprogressive Education, 1996. p. 39- 48.

26. SIQUEIRA, D. F. Estudo comparativo, por meio de análise cefalométrica em norma lateral, dos efeitos dentoesqueléticos e tegumentares produzidos pelo Aparelho Extrabucal Cervical e pelo Aparelho de Protração Mandibular, associado ao aparelho fixo, no tratamento da Classe II, 1a Divisão de Angle. 2004. Tese (Doutorado)-Faculdade de Odontologia de Bauru, Universidade de São Paulo, Bauru, 2004.

27. TWEED, C. H. Clinical Orthodontics. St. Louis: Mosby, 1996. v. 1, p.13-30

28. URSI, W. J. S. Alteração clínica da face em crescimento: uma comparação cefalométrica entre os aparelhos extrabucal cervical, Fränkel (FR-2) e Hersbst no tratamento das oclusões de Classe II, primeira divisão de Angle. 1993. Tese (Doutorado)-Faculdade de Odontologia de Bauru, Universidade de São Paulo, Bauru, 1993 